\section{La elite económica argentina, 1810-1914}

\begin{abstract}
e Politica
DOI 10.1590/1678-987314225203

Roy Hora

RESUMEN

Este artículo analiza los principales rasgos del sector más poderoso de la elite económica argentina del período 1810-1914. El trabajo discute las principales interpretaciones sobre las características y naturaleza de este grupo, pone de relieve algunas de limitaciones de los enfoques más habituales sobre el tema, y sugiere de qué manera conceptualizarlo de forma productiva. Aunque el objeto de este trabajo es la elite económica, todo análisis de este actor supone a la vez una manera de concebir las características del sistema de poder y del entorno económico en el que se desenvuelve la acción de los hombres de fortuna. Por este motivo, este trabajo formula algunas consideraciones generales sobre las características del Estado (argentino) y el capitalismo (pampeano), con el fin de precisar mejor qué tipo de elite económica dominó la producción rural y la economía argentina en el período de crecimiento exportador que se extendió desde la Independencia hasta la Primera Guerra Mundial. El trabajo toma distancia de los estudios que enfatizan la importancia de la dimensión política para explicar el proceso de constitución y reproducción de esta elite económica, enfatizando en cambio los determinantes económicos de este proceso. El ensayo no aporta nueva evidencia empírica, sino una reflexión a partir de la literatura existente.
\end{abstract}

PALABRAS-CLAVE: elite económica; Argentina; siglo XIX; historiografía; economía rural.

Recebido em 18 de Janeiro de 2014. Aprovado em 29 de Agosto de 2014.

\section{Introducción}

$\mathrm{E}$ ste ensayo analiza los principales rasgos del sector más poderoso de elite económica argentina del período de crecimiento agroexportador que se extiende entre la apertura del Río de la Plata al mercado mundial a comienzos del siglo XIX y el estallido de la Primera Guerra Mundial. El trabajo discute las principales interpretaciones sobre las características de este grupo, pone de relieve algunas limitaciones de los enfoques más habituales sobre el tema, y sugiere de qué manera conceptualizado de manera productiva. Aunque el objeto de este trabajo es la élite económica, todo análisis de la naturaleza de este actor lleva implícita una manera de concebir las características del sistema de poder y del entorno económico en el que se desenvuelve la acción de los hombres de fortuna. Por este motivo, el trabajo formula algunas consideraciones sobre las características del Estado (argentino) y el capitalismo (pampeano). Cada uno de estos objetos analíticos posee una gran complejidad, y requiere más atención que la que esta breve presentación les presta. De todos modos, los argumentos que propone este trabajo tienen la intención de estimular la discusión sobre cómo abordar el estudio de la elite capitalista. La perspectiva que adopta esta exploración es la de un historiador, esto es, de un investigador más interesado en la productividad analítica que en la coherencia interna de las perspectivas y los conceptos a discutir.

\section{La elite económica en la literatura histórica}

Los autores que analizan la trayectoria histórica argentina entre 1810 y 1914 suelen prestar gran atención a la clase propietaria. Una economía agraria dinámica, a la vez que signada por la gran propiedad, y en la que los grupos propietarios rurales poseían gran riqueza y visibilidad social, inevitablemente hizo que la clase capitalista (un concepto sobre el que volveremos) tuviese gran relevancia a la hora de explicar los rasgos de esta sociedad. A lo largo de ese 
siglo, además, el peso y la incidencia económica del Estado, aunque lejos de ser insignificantes, fueron considerablemente más reducidas que en períodos posteriores, lo que sin duda contribuyó a resaltar la importancia de los grandes capitalistas. Algo similar se observa al dirigir la atención hacia las clases subalternas, por cuanto la capacidad de los trabajadores y sus organizaciones tanto para incidir en el reparto del producto social como para orientar el curso del proceso económico no posee comparación con el que estos actores alcanzaron desde la segunda posguerra. Por todo ello, el énfasis en la importancia de la elite propietaria como actor central del proceso económico, a la vez que como vía de entrada para explorar las características de la economía argentina, aún si por momentos exagerado, sin duda resulta comprensible y justificado.

La literatura sobre la elite económica del período agroexportador ha dado lugar a dos grandes corrientes de interpretación. Ambas señalan la importancia de los determinantes políticos para explicar la supremacía de este grupo, aunque disienten en algunos aspectos que ahora pasamos a reseñar. Un primer conjunto de trabajos enfatiza la naturaleza agraria de esta elite. Descripta habitualmente como una oligarquía terrateniente, la preeminencia de este grupo, según se señala, no se apoyó tanto en su dinamismo económico como en su capacidad para controlar el Estado e imponer su autoridad sobre la sociedad. Esta elite ejerció un dominio de naturaleza paternalista o clientelar sobre las clases subalternas rurales, y también se impuso sobre las más independientes clases populares urbanas y, desde fines del siglo XIX, también sobre el emergente empresariado industrial surgido en las grandes ciudades de la región litoral. Aun cuando las formas de la dominación terrateniente fueron mutando, suele señalarse que el poder de esta elite no sufrió impugnaciones hasta bien entrado el siglo XX (el período de gobiernos radicales, 1916-30, es motivo de alguna disputa interpretativas). Así, luego de 1810 cobró forma un orden político de fachada republicana, pero cuyas bases de poder estaban enraizadas en la dominación terratenientes. La supremacía de los grandes propietarios rurales es, de acuerdo a esta perspectiva, la principal característica de la dictadura rosista, que impuso su sello al país desde fines de la década de 1820 hasta más allá de 1850. Luego de 1852, cuando la Argentina ingresó en la era liberal y constitucional, el dominio de la elite terrateniente se afirmó sobre nuevas bases, entre los que destaca el fraude electoral y, desde fines del siglo, la represión de las demandas de los trabajadores urbanos surgidas bajo el signo de la "cuestión social". La emergencia de impugnaciones obreras y populares y de reclamos de clase media pusieron bajo presión a la dominación oligárquica, volviéndola más frontal y represiva. Pero gracias a su control sobre el Estado, hasta bien entado el siglo XX el orden oligárquico siguió preservando los privilegios de la elite económica y la gran propiedad.

Distintas líneas de reflexión contribuyeron a forjar esta visión. La primera tiene por protagonistas a integrantes de las elites gobernantes liberales que, interesados en comprender el proceso de formación de la gran propiedad, ya en el siglo XIX comenzaron a estudiar la política de cesión de tierras públicas al dominio privado. Sus trabajos, centrados en el análisis de las leyes de tierra de la era republicana, señalaron cómo la enajenación de este bien público resultó fundamental para la construcción de las grandes fortunas rurales (Avellaneda 1865; Cárcano 1917). El Estado fue, en esta visión, el gran responsable de un proceso de concentración del suelo que colocó a la Argentina en una trayectoria divergente respecto a la de las admiradas sociedades de agricultores independientes - productores familiares prósperos y eficientes, a la vez que altamente integrados al mercado- típicos de las agriculturas de América del Norte.

Los socialistas de las primeras décadas del XX profundizaron esta línea de indagación, que entendían políticamente primordial por cuanto suscribían la idea de que la elite agraria constituía el núcleo duro de la clase propietaria. Pero 
en vez de enfatizar que la política de tierras supuso el despilfarro de los recursos públicos, Juan B. Justo y los orientadores intelectuales de la izquierda parlamentaria dirigieron su atención hacia las consecuencias económicas y sociales del proceso de concentración del suelo. Los instrumentos analíticos que les ofrecía el universo conceptual de la II Internacional dieron forma a esta visión. Lo que para los autores pertenecientes a la elite dirigente liberal podía concebirse como el producto de la baja calidad de la política pública era interpretado por los socialistas como el principal indicador del carácter de clase del Estado argentino, que a sus ojos aparecía dominado por una "burguesía terrateniente" (Oddone 1956).

A partir del estudio de los distintos mecanismos que hicieron posible la apropiación privada de la tierra pública (compra, donaciones, enfitesis, etc.), y de la identificación de sus principales beneficiarios individuales, los socialistas se propusieron poner de relieve la estatura económica de la elite rural e identificar a las principales fortunas territoriales del país. Aquí, la formación de esta clase dominante fue concebida, más que como un derivado de la estructura productiva, como el resultado del sesgo antidemocrático adquirido por el proceso de distribución de tierras, reflejo, a su vez, del influjo de los socialmente poderosos sobre el Estado. Mientras que los liberales habían centrado sus estudios en el análisis de la legislación agraria, los socialistas giraron su atención hacia las fuentes estatales (catastros y registros fiscales) que permitían identificar a los mayores propietarios rurales, determinar la importancia de sus tenencias y, de este modo, definir el perfil y los contornos de la clase dominante. Es importante señalar que los socialistas no realizaron mayores esfuerzos por comprender lógica económica de la elite propietaria, ni se esforzaron por investigar cómo se daba el proceso de acumulación de capital en las grandes estancias, a las que concebían como unidades económicas atrasadas, muchas veces como meras perceptoras de rentas. La premisa de que la propiedad terrateniente, aunque económicamente menos racional y productiva que la pequeña propiedad farmer, había nacido y sobrevivía gracias al control que los terratenientes ejercían sobre el Estado, sirvió para inhibir cualquier exploración encaminada en esa dirección.

En este sentido, pues, la definición de la elite propietaria como una "burguesía terrateniente" estaba destinada a poner de relieve, más que la naturaleza social de los propietarios rurales, el hecho de que este grupo que había crecido en riqueza al amparo del Estado carecía de antecedentes aristocráticos. Pero luego de constatar su condición de producto de la expansión del mercado mundial capitalista, las preguntas de los socialistas no iban dirigidas a entender el comportamiento económico de este actor por cuanto entendían que, si bien su naturaleza histórica era burguesa, su función era similar a la de las clases propietarias rurales europeas de pasado feudal. Al igual que los terratenientes de la Europa continental de los siglos XVIII y XIX, la elite rural pampeana era concebida como un grupo económicamente parasitario. Este énfasis en la clase propietaria rural como un mero perceptor de rentas evidencia el influjo del prisma analítico de la II Internacional, y en particular de los estudios sobre la "cuestión agraria". Como es sabido, las principales contribuciones a ese debate (Engels, Kautsky, Lenin, etc.) giraron en torno a la pregunta por la relación entre el desarrollo del capitalismo agrario y la supervivencia/desaparición/transformación del campesinado, una cuestión fundamental en la definición de la estrategia política de los socialismos europeos de la era previa a la Gran Guerra - y ello porque no sólo en el siglo XIX sino también ya avanzado el XX, el mundo rural alojaba al sector más numeroso de la población y del electorado incluso en la industrializada Alemania; Inglaterra constituye la única excepción significativa a este cuadro pero, debido a la ausencia de partidos social- 
demócratas, la realidad rural de este país no despertó mayor interés en el pensamiento socialismo europeo.

En esa literatura, de gran influencia sobre el socialismo argentino, el problema de los grandes empresarios agrarios siempre quedó en un cono de sombra, opacado por los interrogantes que planteaba la relación entre campesinado y capitalismo. Las decisivas contribuciones de Juan B. Justo, centradas en el estudio de los pequeños productores agrícolas, tuvieron ese foco "campesinista". Y aunque Justo comprendió bien que los "farmers" pampeanos no se parecían a los campesinos europeos, no creyó necesario partir de la misma premisa a la hora de entender a los terratenientes, a los que siempre concibió como meros rentistas. En sus estudios, que dieron forma al Programa Socialista del Campo, se identificaba a la agricultura familiar como el sector productivo por excelencia, señalando la necesidad de liberarlo de la presión de los dueños del suelo (Justo 1901). De allí, pues, que el relato socialista sobre la constitución y características de la elite económica, al insistir en determinantes políticos, tuvo más puntos de continuidad que de ruptura con la crítica liberal a la concentración del suelo.

Finalmente, en la segunda posguerra, cuando los caminos de la reflexión política y de la investigación académica comenzaron a divergir de manera más explícita, es posible constatar la aparición de trabajos más sofisticados desde el punto de vista analítico. Importantes estudios que analizaban la trayectoria histórica del país se realizaron bajo la inspiración de las corrientes intelectuales predominantes en ese tiempo (teoría de la modernización, desarrollismo, dependentismo). Sin embargo, en esos años, la atención de los investigadores más originales y ambiciosos se dirigió en nuevas direcciones, que reflejaban las transformaciones experimentadas por la economía argentina tras el cierre del mercado mundial que siguió a la Gran Depresión, y los dilemas que a partir de entonces enfrentaron sus actores e instituciones. El estudio de los problemas del desarrollo industrial y la formación del empresariado manufacturero opacaron el interés en la elite rural y en el sector rural exportador, que pasó a ser concebido como una rémora de un pasado condenado (por ejemplo, Ferrer 1963). Así, pues, estos trabajos, aunque analíticamente más sofisticados y empíricamente más rigurosos, mostraron poco interés en analizar los logros del crecimiento inducido por las exportaciones, que veían como cualitativamente inferior al promovido por el sector manufacturero, y de cuya potencialidad para promover el desarrollo siempre desconfiaron. De allí que a la hora de interpretar el papel histórico desempeñado por la elite propietaria del período previo a la Gran Depresión, las nuevas contribuciones siguieron compartiendo presupuestos y modos de abordaje forjados varias décadas antes, que enfatizaban el carácter parasitario y la cultura anti-empresarial de los propietarios agrarios.

En este período, por otra parte, también se publicaron investigaciones históricas que prestaban mayor atención a la economía agraria, más cuidadosas y sofisticadas que las escritas hasta entonces - de los cuales el más importante fue quizás el de James Scobie (1964). Estas contribuciones ofrecieron correcciones parciales a las visiones algo impresionistas sobre el proceso de apropiación de la tierra y la concentración del suelo, pero terminaron dando una imagen similar acerca de la naturaleza y las características de la elite propietaria rural (Giberti 1954; Gaignard 1989; Girbal de Blacha 1980). De hecho, todos ellos pueden ser identificados como continuación de esa antigua tradición de estudios "institucionalista" que analizó a la elite terrateniente a la luz de la cuestión de la legislación agraria y la propiedad de la tierra que, renovada metodológicamente, conservó una posición central en la discusión académica hasta la década de 1980, y todavía se mantiene activa (Míguez 1986). 
Aunque dominante, esta perspectiva nunca alcanzó a opacar a la otra interpretación sobre las características de la elite económica de la era agroexportadora que mencionamos al inicio de este apartado. Como en muchos lugares de América Latina, en la posguerra la relación entre la elite rural y el empresariado manufacturero se convirtió en un tema de debate. En los trabajos que acabamos de describir, la burguesía industrial surgida gracias al boom agroexportador de fines del siglo XIX era vista como un grupo subordinado, de intereses cada vez más divergentes respecto a la orientación exportadora impuesta por la elite rural. Desafiando esta visión, otros autores enfatizaron la confluencia de intereses entre las distintas fracciones de la clase propietaria, que se habría estrechado tras el cierre del mercado mundial desde 1929 y el proceso de crecimiento industrial acelerado desde entonces (Peña 1974).

Llevando estos argumentos aún más lejos, un influyente trabajo dado a conocer por Jorge Sábato en 1979 insistió en que esa confluencia no era producto del nuevo escenario madurado tras la Gran Depresión, cuando el mercado interno se convirtió en el motor del crecimiento, sino que tenía raíces más antiguas, pues ya en el siglo XIX la cúspide de la clase propietaria se hallaba conformada por empresarios diversificados, cuyos intereses económicos se desplegaban en distintos sectores de actividad (Sábato 1991). De acuerdo a esta perspectiva, la hegemonía de estos capitalistas no habría tenido que afirmarse contra otras fracciones subalternas de la clase empresaria, lo que habría dado por resultado una elite económica aún más poderosa que la descripta por los autores que enfatizaban su naturaleza terrateniente (Sábato 1991; Schvarzer 1991).

Aunque opuestas en lo referido a las relaciones entre empresarios rurales e industriales, las dos corrientes de interpretación mencionadas coinciden en aspectos sustanciales de la descripción del orden político imperante en el siglo XIX, así como en el lugar de los grandes capitalistas en ese orden. Ambas ofrecen variantes de una misma concepción instrumental del poder que concibe al Estado como un agente dominado por la elite económica. En estos relatos, el gran empresariado - de base terrateniente o de perfil diversificado- colocó al Estado y a las fuerzas políticas a su servicio. No enfatizaremos aquí las debilidades teóricas de la perspectiva instrumentalista del poder que informa estas interpretaciones. Basta señalar que incluso dentro de la tradición marxista, el suelo en el que se forjaron muchas de los estudios mencionados, desde la década de 1980 han ganado terreno las visiones que enfatizan la necesidad de encarar el problema de la relación entre elites económicas y Estado desde una perspectiva atenta a las fuentes de autonomía estatal así como al conjunto de relaciones sociales a partir de las cuales las elites construyen y reproducen sus posiciones de poder (Jessop 1990).

Sin embargo, esta impugnación conceptual a las visiones instrumentalistas no resuelve el problema histórico que nos interesa analizar, por cuanto existan numerosas sociedades en las que el poder político de las elites económicas es muy considerable, y su dominio sobre el Estado, muy estrecho. La América Latina del siglo XIX ofrece numerosos ejemplos de este fenómeno, tales como el México de Porfirio Díaz o el Chile de la república oligárquica (Knight 1986; Bauer 1995). Pero el poder de una elite económica, y su capacidad de controlar recursos y acallar las demandas de los grupos subalternos, más que una premisa, debe ser objeto de una investigación histórica cuidadosa, que explique las razones que lo hicieron posible. Cuando volvemos la mirada hacia el caso argentino con estos interrogantes en mente, observamos que la evidencia histórica acumulada en las últimas tres décadas, antes que constatar, más bien ha desmentido aspectos sustanciales de las visiones que enfatizan la unidad entre Estado y elite económica como la clave de bóveda del orden político decimonónico. De hecho, los mejores estudiosos sobre la política del siglo XIX 
demuestran que la disputa política no se hallaba circunscripta al mundo de los económicamente poderosos. A partir de la ruptura con España en 1810, la vida pública -desarrollada bajo el signo de la guerra de independencia y luego de las guerras civiles-, movilizó a un amplio espectro de actores, de importancia variable a lo largo del tiempo, pero que incluían a vastos sectores de las clases subalternas (Salvatore 2003; Sabato 1998; 2012). Ya sea que se analice la revolución de independencia o la dictadura rosista, o incluso el período de formación del Estado (1850-1880), y por momentos incluso la política del orden oligárquico (1880-1916), constatamos que la política del siglo XIX no puede entenderse sólo atendiendo a los hombres de fortuna y posición.

Esta conclusión, empero, no hace más que poner de relieve la relevancia y complejidad del problema que nos interesa analizar. Pues el hecho de que la disputa por el poder desbordase el campo de los socialmente poderosos invita a preguntarse cómo fue posible que, precisamente en ese período, la elite propietaria lograse alcanzar esa posición económica preeminente que todos los ensayos sobre el tema justificadamente le asignan. En efecto, aún si la elite propietaria no fue el único actor del desarrollo agrario, en los años de la Belle Epoque (1870-1914) este grupo no sólo se convirtió en el más rico de América Latina sino que llegó a ocupar un lugar de relieve entre las clases propietarias más afortunadas del planeta. Si bien la elite argentina no podía comprarse con los ricos británicos y mucho menos con los estadounidenses, que se hallaban en una categoría distinta y superior, algunas de sus figuras más notables alcanzaron a poseer fortunas de escala similar a las de los principales magnates de la Europa Continental (Hora 2012b). Desgraciadamente, muchos de los estudios recientes sobre historia política resultan de limitada utilidad a la hora de comprender cómo la elite económica argentina alcanzó esta posición tan destacada, toda vez que el fuerte énfasis en la autonomía (analítica) de la política que se ha abierto camino en esta literatura ha dado lugar a un renovado interés en las singularidades de la vida pública, pero a costa de desatender la relación entre la elite económica, el Estado y los elites políticas.

Del mismo modo, y en parte como reacción a las visiones tradicionales que prestaban escasa atención a la lógica económica de la actividad productiva, muchos estudios recientes sobre historia económica colocan el foco en el funcionamiento de los mercados y el énfasis en la racionalidad de los empresarios en tanto maximizadores de recursos, desplazando a un segundo plano cuestiones ligadas al contexto en el que se desenvuelve la acción de los capitalistas. En particular, los trabajos de Roberto Cortés Conde y Ezequiel Gallo constituyen un hito en esta evolución (Cortés Conde 1979; Gallo 1983). Más recientemente, la preferencia por escalas reducidas de análisis, como el caso individual, ya sea para estudiar a un empresario o a una empresa, deja en un cono de sombra la cuestión del lugar político de la elite propietaria, y el de las relaciones entre Estado y mercado - véase, por ejemplo, Amaral (1998) y Reguera y Zeberio (2006). Así, pues, ya sea en el terreno de los estudios de historia política como en el de los de historia económica, si el instrumentalismo ha quedado atrás, fue en alguna medida al precio de dejar de lado la pregunta por la relación entre la elite económica, la política y el estado, o de plantearla en niveles analíticos que no ofrecen la mejor perspectiva para responderla.

Las páginas que siguen presentan algunos argumentos y sugieren algunos caminos para avanzar en esta indagación. Gran parte de los estudios tradicionales sobre el poder terrateniente han concentrado su atención en las organizaciones representativas del interés sectorial - de las cuales la más relevante del período bajo estudio es la Sociedad Rural Argentina (Smith 1969; Solberg 1971). Este trabajo, en cambio, parte de la premisa de que resulta más productivo dirigir la atención hacia el contexto más amplio en el que se desenvolvió la acción de los grandes terratenientes que conformaban el núcleo de la elite 
propietaria. Sugiere que toda discusión sobre la gravitación y las características de este grupo debe trascender los casos individuales y al mismo tiempo tomar distancia de los razonamientos tautológicos tan frecuentes a la hora de aquilatar el poder de las elites - que entienden el poder de los poderosos como un dato antes que como un problema.

Este trabajo suscribe la visión tradicional que concibe a los grandes propietarios rurales como el núcleo de la elite económica en el período 1810-1914. Pero sugiere que es preciso periodizar con cuidado el proceso de emergencia y las transformaciones experimentadas por este actor, ya que sus rasgos cambiaron con el tiempo. Para captar la naturaleza y las principales características de la elite económica, se enfatiza la importancia de los determinantes económicos. Se argumenta que el estudio de la elite económica argentina debe ser, por definición, un estudio de los rasgos económicos y de la posición económica de este grupo, sobre todo para el período a veces denominado oligárquico. En una economía dinámica y en expansión, en la que se observan muchas trayectorias de ascenso y una considerable renovación de la elite capitalista, la definición de las fronteras que separan a la cúspide de la clase propietaria de otros actores económicos menos poderosos es analíticamente menos relevante que el análisis de la lógica de la economía agraria de la que esta elite obtuvo sus principales beneficios. De allí que los estudios prosopográficos tampoco resulten particularmente productivos para abordar la historia de este grupo. Cuando dirigimos la atención hacia la relación entre la elite económica y el orden político, se imponen consideraciones similares. Como veremos, la posición dominante de los grandes terratenientes no puede ser explicada a partir de su supuesto dominio sobre el Estado. En cambio, se entiende mejor cuando consideramos la fortaleza de la posición de este actor en la esfera económica y social. Pero estos razonamientos deben ser contextualizados, ya que a lo largo del siglo XIX la relación de los hombres de fortuna con el Estado experimentó cambios de consideración. Prestar atención a estas cuestiones es importante para la definición de la naturaleza y características de esta elite, y para definir cuáles son las mejores estrategias para abordar su estudio.

\section{Formación y características de la elite rural}

El análisis de la elite económica debe prestar atención a dos momentos: la etapa posindependiente (1810-1860) y el período dorado de crecimiento exportador (1860-1914). Veamos rápidamente los principales rasgos de cada una de ellas.

III.1. $1810-1860$

El avance de los propietarios rurales hacia el centro de la elite económica fue el resultado de la independencia y la apertura al mercado mundial. Antes de la Revolución de Mayo, el núcleo más poderoso de la elite económica no estaba vinculado a la tierra sino a la actividad mercantil (Halperin, 1972; Mayo, 1995a; 1995b). Como mostró Tulio Halperin en un conocido trabajo, la independencia cambió este cuadro, creando condiciones para el ascenso terrateniente (Halperin Donghi 1963). Las guerras de 1810-20 afectaron el nexo con la minería altoperuana y al comercio a distancia, privando a la elite colonial de su principal fuente de ingresos. Por su parte, la apertura comercial consagrada en 1810 colocó a este grupo ante la competencia de los comerciantes europeos arribados a la región tras el fin del monopolio comercial español. Fracturada la coraza política que les había ofrecido el mercantilismo, en los agitados años que sucedieron a 1810 la mayor parte de las fortunas coloniales se derrumbaron (Adelman 1999). Mientras tanto, el comercio libre colocó a la economía rioplatense en la órbita de la economía atlántica. Estimulado por un mercado 
externo en expansión y altos precios para sus productos (primero cueros y desde la década de 1840 también lanas), comenzó un proceso de crecimiento agrario destinado a prolongarse por más de un siglo.

Dentro del universo de empresarios que crecieron en importancia gracias a esta expansión productiva, dos tipos de figuras merecen distinguirse. Por una parte, capitalistas que ya ocupaban posiciones relevantes en el período colonial, que movieron recursos desde el comercio a la producción agraria (Hora 2005a; 2005b; 2012a). En segundo lugar, las oportunidades que ofrecía el sector rural dieron lugar a la constitución de numerosas fortunas nuevas que, vistas en conjunto, ponen de relieve el elevado grado de renovación que la elite económica experimentó gracias al proceso de crecimiento agrario. Ello no dio lugar a la formación de dos grupos distintos. Con frecuencia, los empresarios de origen colonial que se volcaron a la producción rural mantuvieron intereses en otras actividades; muchos nuevos, por su parte, una vez que alcanzaron cierta escala, giraron capital desde el campo a la ciudad. Tanto la renovación del universo de empresarios como la diversificación de activos se hallan relacionadas con la fuerte inestabilidad institucional que caracterizó a la economía de la región en la primera mitad del siglo XIX. Los conflictos políticos, las guerras civiles y externas, los bloqueos que por largos años sufrió el comercio de exportación, la desvalorización del papel moneda local, aconsejaban no depender de una única fuente de ingresos, por más atractiva o dinámica que ésta fuera. Al mismo tiempo, la inestabilidad institucional también impidió la formación de un sistema bancario que ofreciera una alternativa para preservar recursos y ahorros, dejando como únicas alternativas el atesoramiento o la diversificación de inversiones. Por este motivo, la transformación en los patrones de inversión que sucedió a la independencia puede describirse como la incorporación de una nueva actividad productiva que, aunque de importancia capital, no eliminaba sino que se sumaba a otros emprendimientos: comercio de importación y exportación, actividades financieras y mercantiles y, sobre todo, renta urbana. Aun cuando el grado de diversificación es motivo de cierta discusión, es indudable que la elite económica de la primera mitad de siglo no puede describirse como una elite exclusivamente terrateniente (Garavaglia, 1999; Gelman y Santilli 2006; Hora 2006).

El crecimiento exportador se apoyó sobre la incorporación de tierra. A lo largo de esas décadas, la frontera productiva avanzó sobre territorio indígena, empujando a los pueblos originarios hacia el sur y el oeste. Este proceso de conquista territorial produjo conflictos pero, dado que la población indígena que habitaba en esas regiones era escasa, hasta la década de 1850 los enfrentamientos tuvieron casi siempre baja intensidad. Ello permitió incorporar nuevas tierras sin grandes esfuerzos militares o fiscales, estimulando el uso productivo de este recurso, y dando primacía a los empresarios por sobre el Estado. El bajo costo de la incorporación de tierras de frontera, sumado al primitivismo tecnológico de la explotación ganadera y el elevado costo de la fuerza de trabajo, favorecieron la conformación de grandes propiedades - en especial en los distritos más alejados. La consecuencia fue la afirmación de la gran propiedad. Sin embargo, la abundancia de tierras y la ausencia de economías de escala también contribuyeron a la supervivencia e incluso a la expansión de pequeñas explotaciones familiares, predominantes en número y muy significativas en cuanto a su contribución a la generación del excedente agrario. Pese a la temprana advertencia de Jonathan Brown sobre la importancia de este fenómeno (Brown 1979), sólo en los últimos años los historiadores han comenzado a asignarle a los emprendimientos familiares la relevancia que merecen, tanto en el plano demográfico y económico como en el político (Gelman y Santilli 2006). Muchos de estos pequeños productores operaban dentro de grandes propiedades, y otros carecían de títulos perfectos sobre el suelo - 
costosos y difíciles de obtener para los actores de escala local, además de innecesarios hasta al menos la mitad de siglo. De allí que permanecieran invisibles en los estudios centrados en la consulta de registros catastrales.

El uso de las fuentes catastrales, pues, sesgó la mirada de los historiadores, que por largo tiempo atribuyeron a la elite propietaria de la primera mitad del siglo XIX una predominancia social y económica que nunca poseyó. La heterogeneidad del universo social pampeano se hizo aún menos visible por cuanto las tensiones entre grandes y pequeños, y su disputa por recursos, no tuvieron mayor relevancia a lo largo de este período, en primer lugar porque sus relaciones se dieron en un escenario caracterizado por la abundancia de tierra barata y una fuerza de trabajo escasa y móvil, capaz de defender su independencia productiva o reclamar altas remuneraciones por sus servicios.

Desde muy temprano, por otra parte, los incentivos mercantiles tuvieron una importancia decisiva para orientar el comportamiento de todos los agentes de la actividad productiva. A diferencia de los casos "clásicos" europeos o de las tierras altas americanas, en la pampa el avance de la economía de mercado no trajo la destrucción de antiguas comunidades campesinas o el avasallamiento de derechos populares consuetudinarios por parte de estancias o haciendas. Por el contrario, el auge exportador favoreció la intensificación de las relaciones de las familias productoras con el mercado, convertido cada vez más en el destino de su producción y en el proveedor de bienes básicos de consumo. Poco después de la independencia, incluso los asalariados más humildes vestían textiles ingleses y habían incorporado a sus costumbres el consumo de alimentos y bebidas importados. En este contexto, las limitaciones al avance de la economía capitalista dependieron menos de resistencias populares a la proletarización o al avance del mercado que del lento y dificultoso despliegue de instituciones estatales (banca, derechos de propiedad absolutos) y de un sistema de transporte capaz de acelerar la integración del mercado - y es por ello que este proceso sólo terminó de cobrar forma en la segunda mitad del siglo. En rigor, las disputas entre pobres y ricos, cuya intensidad es motivo de debate, no tuvieron mayor incidencia sobre la trayectoria de la economía pampeana por cuanto todos los actores acompañaron la expansión de la economía de mercado, en primer lugar porque obtuvieron provecho del incremento del ingreso generada por el crecimiento exportador (Hora, 2010). Y ello le otorgó una amplia base social a la orientación exportadora consagrada tras la apertura comercial. En síntesis, las grandes estancias no fueron más que el núcleo más visible y poderoso de un sector exportador complejo y diversificado, capaz de comprender una multiplicidad de actores e intereses (Brown 1979; Hora 2010).

Giremos la atención hacia la relación entre la elite económica y el Estado. Dos aspectos merecen especial atención. El primero puede formularse como la dependencia estructural del Estado respecto del sector exportador. Hasta 1810, el Estado colonial había protegido y promovido la extracción de metal precioso de las minas del Alto Perú, pues esta actividad era el motor de la economía virreinal y la principal fuente de ingresos para el fisco; pobre y despoblada, y de escasa importancia geopolítica, la campaña rioplatense no estaba entre las prioridades del Estado borbónico (salvo, y por razones geopolíticas, en la región lindante con el imperio portugués). Tras la independencia y la pérdida del Alto Perú, esta situación se modificó radicalmente, pues entonces la producción rural se perfiló como la única alternativa para reorganizar la economía y la fiscalidad de la nueva república, sobre todo por su fuerte dinamismo exportador. El estímulo al sector exportador se convirtió en un objetivo prioritario para todos los gobernantes, cualquiera fuese su signo político, al menos en dos aspectos. Por una parte, la expansión económica contribuía a devolver a los hombres a la disciplina del trabajo quebrada por la conflictiva transición entre colonia y república. Y, más importante, el cobro de gravámenes al comercio ex- 
terior (cuya dependencia de la suerte de las exportaciones rurales era directa) se convirtió en la principal fuente de ingresos del fisco. A lo largo del siglo XIX, más de dos tercios de los ingresos fiscales tuvieron este origen, con lo que se tejió un lazo estructural entre el crecimiento exportador, la promoción de los intereses de sus agentes y la consolidación del Estado (Halperin Donghi 1995).

Si la relación entre Estado y elite económica se definía a partir de este nexo estructural, también se hallaba sometida a otras determinaciones más específicas. En relación a este punto cabe formular una breve consideración sobre la cuestión de la autonomía del Estado republicano. En un Estado en formación, surgido en el marco de prolongados conflictos armados que movilizaron a amplios sectores de la población, las fuentes de esta autonomía no fueron burocráticas sino políticas. El Estado independiente fundó su legitimidad en la soberanía popular, y debió reclamar la obediencia de una sociedad que había sido profundamente movilizada por las guerras de independencia y más tarde por las civiles e internacionales. A su vez, la intensa politización que dividió a la sociedad, en especial en las décadas de 1830 y 1840, signó el comportamiento del Estado. La retórica (y en menor medida) la práctica antielitista caracterizaron a la administración de Rosas (Myers 1995; Salvatore 2003). Así, por ejemplo, en 1840-41, además de agresiones simbólicas, parte considerable de la elite estanciera bonaerense sufrió la expropiación de sus propiedades, que permanecieron bajo control estatal hasta la caída del dictador (Gelman y Schroeder 2002). Esta iniciativa no estaba dirigida contra la clase propietaria en su conjunto, sino contra sus sectores políticamente disidentes, pero de hecho afectó a muchos de ellos, y en particular a sus integrantes más poderosos. Y pese a que en la década de 1820 el gobierno intentó dar forma a un nuevo orden legal capaz de asegurar los derechos de propiedad absoluta, estimular la circulación del papel moneda y promover la formación de un mercado de capitales, estas iniciativas pronto cayeron víctimas del recrudecimiento de la guerra civil (Adelman 1999).

La evaluación de la incidencia de la autonomía del Estado rosista sobre la elite económica depende, en gran medida, de la escala de análisis a adoptar. Es indudable que las iniciativas de los gobernantes alteraron drásticamente la composición de la elite económica, enviando a muchos propietarios al exilio, destruyendo o expropiando grandes fortunas y abriendo el camino para la construcción de otras, crecidas al abrigo del poder estatal. En algunos distritos rurales, el ocaso de los grandes nombres fue dramático (Gelman y Schroeder 2002). Todo ello sin duda afectó el crecimiento económico y demoró la consolidación de la economía capitalista. Pero los efectos del comportamiento estatal sobre la elite económica se revelan menos significativos. En muchos aspectos, el rosismo promovió la renovación de la elite propietaria, no su destrucción. Es indudable que el elevado gasto estatal de la era de "la guerra permanente" supusieron una erogación que la elite económica no recibió con beneplácito (Halperin Donghi 2005). Por otra parte, la igualación social promovida por la retórica republicana, que importantes segmentos de las clases populares hicieron suya, recortaron la autoridad social de los grupos propietarios (Salvatore 2003). Del mismo modo, la ausencia de un régimen de derechos de propiedad consolidado afectó el proceso de acumulación y las estrategias de inversión de la elite propietaria.

Sin embargo, en esas décadas la gran propiedad no retrocedió sino que se consolidó. En una economía escasa en hombres y capital, la gran estancia ganadera era el principal agente de la expansión de la frontera productiva. Las grandes estancias fueron el factor más dinámico (aunque no el único, puesto que su expansión se apoyó sobre los pequeños productores que poblaban la campaña) a la hora de expandir la producción, sobre todo en las regiones de frontera, donde desempeñó un papel crucial en la consolidación del dominio de los 
colonizadores blancos sobre tierras indígenas. Así, pues, en un marco signado por una considerable fragilidad institucional, pero también por un amplio consenso social en torno a las ventajas de la orientación exportadora que favorecía la formación de grandes fortunas rurales, el conflicto político tuvo más incidencia sobre la composición de la elite que sobre los rasgos de este grupo. Y ello hizo que, hacia mediados de siglo, en el umbral de la era liberal, la elite económica tuviese un perfil más rural, y fuese más poderosa, que dos o tres décadas antes.

III.2. $1860-1914$

Hacia 1900, la elite económica pampeana alcanzó su momento de esplendor, convirtiéndose en la más opulenta de América del Sur. El ascenso de este grupo se aceleró en el último tercio del siglo XIX, al calor de la veloz expansión del sector exportador. Entre 1880 y 1914, las ventas externas se multiplicaron unas diez veces, convirtiendo a la Argentina (que poseía menos del 10\% de la población de la región), en la responsable de cerca de un tercio de las exportaciones de América Latina (Bulmer-Thomas 1994). Este crecimiento fue, en primer lugar, el resultado de la aceleración del proceso de integración del país a la expansiva economía atlántica. Nuevos sistemas de transporte (barco a vapor y ferrocarril) ampliaron los mercados para la producción exportable pampeana, mientras que el desarrollo del mercando internacional de capitales y el incremento del flujo migratorio aportaron los recursos de capital y la energía humana que permitieron el cambio tecnológico y el crecimiento del producto. La expansión de los mercados europeos para la lana, y luego la carne (ovina y vacuna) impulsó una profunda renovación de la ganadería, realizada a través de inversiones en la mejora de praderas y ganados. En estas últimas dos décadas del siglo, el veloz desarrollo de la red ferroviaria también hizo posible un dramático crecimiento de la producción granífera, que se prolongó hasta fines de la década de 1920 (Míguez 2006; 2008; Hora 2010).

Contra la visión que enfatiza el carácter socialmente cerrado de la "oligarquía terrateniente", hay que señalar que el dinamismo de la economía exportadora dio lugar a la emergencia de un número muy considerable de nuevas fortunas rurales, muchas de ellas de origen inmigrante. La renovación de la elite propietaria fue muy significativa, y algunos de sus nuevos integrantes alcanzaron la cima de la clase propietaria nacional (inmigrantes de muy humildes orígenes como Duggan, Santamarina o Duhau, por ejemplo, amasaron fortunas de rango similar a las de Anchorena, Alzaga o Pereyra, las familias propietarias de mayor fortuna de la primera mitad del siglo). La elite propietaria se renovó también en otros dos sentidos. El nuevo marco para el desarrollo de la actividad empresarial en el sector rural dio lugar a la aparición de nuevos tipos de empresarios. En esos años cobró gran visibilidad la figura del estanciero modernizador, promotor del cambio productivo y activo participante de la vida asociativa rural. Y este cambio en el estatus público del gran estanciero se acompañó de una creciente especialización en la actividad rural. Los capitalistas del medio siglo que sucedió a la independencia habían apostado a la diversificación para atenuar el riesgo. En cambio, la conducta de los estancieros del último tercio del siglo XIX y de las primeras décadas del siglo XX se caracteriza el énfasis en la profundización sectorial. En un contexto de mayor estabilidad institucional y excelentes perspectivas de crecimiento en el mediano y largo plazo, estos empresarios definieron sus estrategias de inversión de modo de explotar al máximo la excepcional dotación de recursos naturales de la región a través de la especialización agraria. En ese contexto cobró especial importancia la renta del suelo, que dio lugar a la emergencia de un conjunto de grandes propietarios rentistas. Pero junto a este grupo, y más importante, 
también nació una elite económica más poderosa, más dominada por el espíritu de innovación, y también más especializada (Hora, 2001).

Las transformaciones del capitalismo argentino empujaron a la elite empresarial rural en este sentido, por cuanto acotaron el atractivo de las estrategias destinadas a minimizar riesgos. Desde 1853, los gobernantes liberales promovieron la sanción de un régimen de derechos de propiedad que reforzó los derechos sobre la tierra y estimuló la inversión extranjera (Adelman 1999). Ello creó condiciones propicias para el desarrollo de un sistema bancario que ya en la década de 1880 se convirtió en el más avanzado de América Latina (Marichal 1995; Regalsky 1995). Desde entonces, el atractivo del negocio del crédito pre-bancario, en el que tantos capitalistas habían incursionado en décadas pasadas, se redujo. Al mismo tiempo, el crecimiento y la sofisticación de los mercados locales e internacionales de mercancías, así como el formidable aumento del comercio de exportación, dieron lugar a la aparición de poderosas empresas, algunas de capital nacional y otras extranjeras, con una presencia dominante en rubros tales como la consignación y acopio de ganados y frutos del país, la importación de productos manufacturados extranjeros, la exportación de lanas y cueros, y algo más tarde, de carnes y granos. Estas empresas (las más conocidas, pero no las únicas, fueron los frigoríficos y las exportadoras de cereales) organizaron una densa red que les permitió controlar el grueso de la actividad de comercialización y/o financiación de la producción agraria (Marichal 1998). Como consecuencia del avance de estas empresas, sólo unos pocos grandes terratenientes lograron mantener cierta presencia en la esfera de la circulación, aunque modesta y en general limitada al mercado interno. Los estancieros que debieron ceder posiciones en los circuitos de comercialización y financiación se acomodaron sin grandes conflictos al nuevo escenario. Para muchos de ellos, la alta rentabilidad garantizada por la actividad rural seguramente operó como un incentivo para concentrarse en la producción (Hora 2002).

La formación de esta elite económica más poderosa, a la vez que más moderna y especializada, no fue sólo el producto de las transformaciones económicas que acabamos de reseñar. Para entender este proceso es necesario formular algunas consideraciones sobre la relación entre elite económica y Estado. Como ya hemos señalado, muchas veces se ha considerado que el control del Estado por parte de esta elite terrateniente constituyó un rasgo típico del orden político de 1880-1916. Es indudable que ése fue el momento más oligárquico de la trayectoria política del país. En esos años, las clases populares perdieron presencia en la vida pública se retrajo, al mismo tiempo que crecía el poder del Estado y el margen de maniobra de la elite dirigente. Estas tendencias oligárquicas no se limitaron al campo político. En este período la elite social alcanzó mayor visibilidad y reconocimiento, lo que contribuyó a acentuar los rasgos jerárquicos y elitistas de la vida pública (Losada 2008).

De allí no se sigue, sin embargo, que el sector más poderoso de la elite económica, el de los grandes terratenientes pampeanos, acrecentase su capacidad de incidencia sobre el Estado. Cuando observamos el cuadro más amplio, se pone de relieve que el Estado adquirió más autonomía frente a este grupo. Ese período debe ser entendido como una etapa en la que el Estado se fortaleció gracias al aumento de su poder coercitivo (un proceso que venía al menos desde la Guerra del Paraguay de 1865-70) pero también como resultado de la ampliación de sus bases de sustentación que, sumados, acrecentaron su capacidad para penetrar y orientar a la sociedad. Bendecido por un contexto internacional muy favorable, el crecimiento económico contribuyó a atenuar las disidencias políticas y los cuestionamientos a la elite gobernante, que desde 1880 encontró más espacio para promover sus proyectos de desarrollismo autoritario. Desde el punto de vista político, sin embargo, el núcleo fundamental de los apoyos a la 
coalición gobernante no se reclutaron entre la elite económica pampeana sino que provinieron de las más pobres oligarquías del interior. Desde la presidencia de Roca (1880-86), estos grupos pasaron a integrar el núcleo de los elencos estatales. Al expandir sus apoyos, el Estado se volvió más nacional, y de este modo atenuó su dependencia de la base política porteña que lo había constreñido en el pasado. El PAN, el partido que gobernó al país entre 1880 y 1916, sacó del centro del escenario a las agrupaciones partidarias de Buenos Aires, que en adelante debieron convivir con nuevos actores. Así, pues, dotada de amplios apoyos en el interior y en la propia maquinaria estatal, la nueva elite dirigente conquistó mayores márgenes de autonomía respecto de la elite económica pampeana.

Ello se reflejó en distintos planos. Se hizo visible en la orientación de la política económica, que se tornó más proteccionista, contrariando los deseos y los intereses de la elite estanciera (Hora 2009b). Algo similar se observa en relación a la orientación del gasto público que, en un país fiscalmente centralizado como la Argentina (y a diferencia de Brasil), se hacía desde la capital. El gasto estatal nunca benefició tanto a las regiones del interior atrasado como en la etapa 1880-1916, particularmente en la primera mitad de este período. La promoción de los intereses políticos y económicos de las oligarquías del interior atrasado (y en alguna medida también de las regiones de las que estos actores proveían) en definitiva pesaba sobre la región pampeana y su sector exportador (Llach 2007).

Sin embargo, esta trasferencia de recursos no debe entenderse como un juego de suma cero. Pese a que la formación de instituciones estatales más poderosas impuso una relación más mediada con las clases propietarias, y a que este cambio se vio reflejado en la política económica, la elite propietaria pampeana también obtuvo importantes ventajas de la consagración del orden oligárquico. Gracias a su capacidad para atenuar el conflicto regional y para afirmar la autoridad del Estado, el orden oligárquico le dio mayor estabilidad institucional al país. Merced a su mayor margen de maniobra, en especial frente a las demandas provenientes desde abajo, las iniciativas de esta elite dirigente contribuyeron a consagrar un régimen de derechos de propiedad favorable a los poderosos, a estimular el desarrollo del mercado de capitales, y a favorecer la expansión de las redes de transporte. Y, en una etapa de acelerada expansión de los flujos internacionales de capital, mercancías y trabajo, ello creó condiciones muy propicias para promover la acumulación de capital. El crecimiento dependió de formas de articulación política que no deben tomarse como un dato natural (el caso de Uruguay, que tuvo una performance más pobre en este período, en parte como resultado de su incapacidad para poner fin a sus conflictos armados, así lo muestra). En síntesis, aún si la formación de una esfera política más autónoma y más compleja erigió nuevas barreras entre los hombres de fortuna y el alto mundo político, este arreglo fue capaz no sólo de proteger sino también de potenciar los intereses propietarios.

$\mathrm{Si}$ al interior del Estado se observan fuerzas que pugnaban por orientar el gasto público en distintas direcciones, los intereses de la elite propietaria no debieron enfrentar desafío de otros actores de la sociedad. Con frecuencia, los estudios que enfatizan el sesgo pro-exportador de la política pública suelen atribuir esta característica al poder de presión terrateniente. En rigor, y al igual que en la primera mitad de siglo, la base social de este orientación era más amplia. Los grandes terratenientes, que controlaban menos de un cuarto de la superficie en explotación, conformaban la cúpula de un sector rural diverso en términos sociales y productivos, pero carente de divergencias internas de importancia. Es importante enfatizar que la primacía terrateniente no era producto de una hegemonía social. Ni los rasgos estructurales ni la historia de esta sociedad de frontera habían favorecido la constitución de lazos perdurables en- 
tre la elite propietaria y los grupos intermedios y bajos de la sociedad rural, capaces de ser explotados políticamente (Hora 2001).

De todas maneras, ello no era necesario, pues tanto los grandes productores como los agricultores y ganaderos de menor envergadura coincidían en la defensa de un conjunto de reglas e instituciones que regulaban la producción rural: bajos impuestos, buenos servicios de transporte, una policía eficiente, una política comercial que abriese nuevos mercados, etc. En muchos aspectos, lo que beneficiaba a los grandes terratenientes también favorecía al resto de los agricultores y ganaderos de la pampa. Por este motivo, los reclamos de la elite terrateniente habitualmente contaban con la adhesión, o al menos la neutralidad, del resto de los actores vinculados a la economía de exportación. Gracias al muy elevado volumen de sus ingresos, producto de la renta diferencial a escala internacional captada por la economía agraria argentina, hasta el fin del período que estamos considerando no se verificaron grandes disputas entre asalariados y propietarios, ni entre arrendatarios y terratenientes. Desde el cambio de siglo, los socialistas agitaron en favor de una reforma de la tenencia del suelo, pero sus iniciativas no encontraron eco en los actores que supuestamente debían beneficiarse del avance de este programa democratizador. Salarios más elevados que los del sur y centro de Europa y oportunidades de "hacer la América" fueron más fuertes que el llamado a la solidaridad de clase o a la lucha contra los privilegios de los poderosos (Adelman 1989). En síntesis, el poder de los grandes propietarios que conformaban el núcleo de la élite económica derivaba, en primer lugar, de su lugar como la cumbre visible y cohesionada del sector más dinámico de la economía argentina, de cuya capacidad expansiva se beneficiaba la actividad económica del país en su totalidad, así como también las finanzas del propio Estado.

Definir el problema de esta manera obliga a una breve consideración sobre la escala de análisis y la representatividad de los casos que son objeto de interrogación. Con frecuencia, los estudios que enfatizan el carácter políticamente constituido de la preeminencia de la elite económica suelen razonar a partir de la generalización de casos particulares. Es en este nivel que parece observarse de manera clara la capacidad de los poderosos de manipular el Estado. Así, por ejemplo, suelen invocarse ejemplos como el presidente Roca (1880-86 y 1898-1904), que logró incorporarse al grupo de grandes terratenientes gracias a su capacidad para apropiarse de tierra pública, lo que pondría de relieve la naturaleza oligárquica de ese régimen. Sin embargo, es dudoso que la figura políticamente más prominente del orden oligárquico puede ser concebida como un ejemplo representativo del tipo de actores que nos interesa analizar. Más importante, el énfasis en los razonamientos que ofrecen conclusiones generales a partir del estudio de personajes singulares desvía la atención del estudio de los determinantes más amplios que moldaron la relación entre Estado y elite económica, y, por tanto, no nos dicen mucho sobre la naturaleza y la posición estructural de este grupo.

El ejemplo que acabamos de mencionar sirve para constatar que las estructuras políticas del régimen oligárquico sirvieron como vehículo a una antigua tradición de acercamiento personal al favor del Estado, cuya acción ya se observa en la primera parte del siglo. Pero si dejamos de lado toda tentación inductivista y colocamos a estas prácticas en una perspectiva más amplia, se advierte que en la etapa dorada del crecimiento exportador, 1880-1914, su gravitación fue mucho menor que en el medio siglo posterior a la independencia. La capacidad de obtener favores del Estado resulta importante para explicar el veloz enriquecimiento de algunas figuras públicas, pero no para entender la relación entre empresarios y Estado, o la posición de estos actores en la cima de la economía agraria. Ya hemos señalado que, dentro del sector rural, los grandes propietarios no enfrentaban desafíos que, eventualmente, podían 
haber dado lugar a disputas políticas capaces de torcer la política pública en contra de la elite propietaria. Y ahora agregamos que lo que resulta característico de las décadas del cambio de siglo no es el incremento sino la disminución de la dependencia de la economía rural pampeana (y por tanto de las fuentes de poder económico de la elite) respecto de los bienes y servicios provistos por el sector público. Sin duda, la ausencia de un programa de distribución democrática del suelo resultó decisiva en la definición del patrón de tenencia de la tierra que le permitió a la elite propietaria convertirse en el principal beneficiario del proceso de crecimiento exportador. Pero más allá de esta constatación -cuyas razones ya hemos mencionado- advertimos que, contra lo que se ha sugerido muchas veces, en este período la relación entre la clase propietaria y el Estado adoptó formas más institucionalizadas y, además, la dependencia de los poderosos respecto del Estado se redujo de forma ostensible.

Gracias en parte a sus ventajas naturales (suelo, clima, localización) sobre otras regiones de agricultura templada, las empresas agrarias pampeanas producían a costos más bajos que los internacionales. Ello les aseguraba elevados márgenes de ganancia sin necesidad de gran apoyo del sector público. Ya sea que se lo formule en el lenguaje de las ventajas comparativas o en el de la renta diferencial a escala internacional, es claro que era en el plano de la calidad de los recursos naturales, y no en el del orden político favorable a los estancieros, donde se encontraba la clave fundamental del éxito de las empresas agrarias pampeanas (Laclau 1969). La conquista del exigente mercado británico para la carne argentina tuvo este determinante, lo mismo que el avance del cereal pampeano sobre el mercado mundial. Y es esta misma clave la que explica el interés de los inversores extranjeros en la creación de la infraestructura necesaria para atender los requerimientos de la economía exportadora, pues también había lugar para que ellos reclamaran su tajada del excedente producido por las diferencias de precios entre los costos de producción locales y los internacionales. El ejemplo de las grandes compañías ferroviarias es al respecto revelador. Para la década de 1880 estas firmas, que en sus inicios habían reclamado asistencia estatal, ya no mostraban mayor interés en ella, y se lanzaban a una fuerte política de expansión atraídos por las altas expectativas de rentabilidad que ofrecía la provisión de servicios de transporte orientados a satisfacer la demanda generada por la economía de exportación y la expansión del mercado interno (Lewis 1983). Otro tanto sucedió, algunos años más tarde, con las empresas frigoríficas que procesaban productos pecuarios. Para fines de la década de 1890 estas firmas ya se encontraban sólidamente establecidas y trabajaban con beneficios seguros y crecientes (Hanson 1938).

Por otra parte, el tipo de inserción de la economía de exportación en el mercado mundial dejaba escaso margen para la intervención estatal. Argentina exportaba bienes que competían con los de otras regiones de agricultura templada, así como también con la producción doméstica de sus principales compradores. En consecuencia, y a diferencia de lo sucedido con el café de Brasil, que dominaba el mercado internacional de este producto, la agricultura pampeana no gozaba de posiciones monopólicas en el mercado mundial, y por tanto no podía manipular la oferta en su favor (Topik 1987). Su dinamismo se fundaba en su capacidad para producir a costos más bajos que sus rivales -agricultores de la cuenca del Danubio, las estepas rusas y las praderas de América del Norte-, y la intervención estatal en la comercialización de la producción, en caso de haberse intentado, no podría haber modificado este panorama. Por este motivo, los productores no la solicitaron, ni mostraron resistencia alguna frente al crecimiento de las grandes firmas comercializadoras extranjeras que desde la década de 1880 fueron desplazando a las pequeñas casas comerciales que habían servido al comercio internacional durante la 
mayor parte del siglo XIX. En general, el avance de los grandes oligopolios cerealeros fue bien recibido por los productores porque a lo largo de estas décadas de fuerte expansión económica y de elevados precios, los esfuerzos de estas firmas para estimular la demanda de sus servicios las obligó a establecer relaciones que tenían por base la percepción de ganancias elevadas para todos los actores involucrados en el negocio. Sólo desde las postrimerías de la Gran Guerra, cuando los mercados externos comenzaron a cerrarse para la producción argentina y los precios descendieron, los productores empezaron a advertir los inconvenientes implícitos en esta desigual relación. Recién entonces se descubrieron prisioneros de unas pocas empresas que podían descargar sobre sus ellos los ajustes del mercado. A partir de ese momento, los estancieros comenzaron a peticionar, aunque sin mayor resultado, el apoyo del Estado.

Tampoco en el plano de la oferta laboral la política pública fue relevante para afirmar los privilegios de la elite propietaria. En lo fundamental, las necesidades de fuerza de trabajo de la economía agraria pampeana encontraron respuesta a través de mecanismos puramente mercantiles. La Argentina tenía una larga experiencia de inmigración espontánea, que en la segunda mitad del siglo XIX tomó mayor impulso. Desde la década de 1850, la ideología estatal se volvió pro-inmigratoria, y en sintonía con este cambio el Estado federal comenzó a invertir dinero para atraer trabajadores europeos. Los recursos destinados a este programa no fueron muchos, y es dudoso que, aún si crecían, hubiesen tenido mucha incidencia sobre el volumen y la orientación del flujo migratorio. En la década de 1880 el Estado abandonó definitivamente el proyecto de invertir para estimular la llegada de europeos. Tras la retirada del Estado, el flujo no disminuyó sino que aumentó, alcanzando su pico en el período 1900-1913. En este punto se observa otro contraste con la economía cafetalera paulista, donde la atracción de colonos europeos siempre fue más problemática, suscitó mayores conflictos, y requirió mayor apoyo estatal (Holloway 1980). En síntesis, fueron las oportunidades ofrecidas por la expansión económica, y no la política pública, la que explican uno de los procesos migratorios más notables del mundo decimonónico. Aunque los empresarios solían quejarse del alto costo de la fuerza de trabajo (típica de una economía de frontera), el nivel de remuneraciones nunca constituyó una verdadera presión sobre la renta el suelo o la ganancia empresaria, por lo que los empleadores terminaron aceptando convivir con una fuerza de trabajo que percibía altos salarios. Desde la perspectiva de estos actores, la gestión de las relaciones laborales tampoco reclamaba mayor participación estatal. A diferencia de lo sucedido en el medio urbano, en el campo no hubo reclamos de intervención estatal en la regulación del mercado de trabajo o de arrendamientos hasta más allá de 1910 .

La provisión de crédito, liderada por la banca estatal, se erige quizá como la única excepción parcial a esta norma de una economía fuertemente orientada por el mercado. Los principales bancos públicos, el Nacional y el Hipotecario, se convirtieron en importantes auxiliares de los empresarios del sector agrario (Toulchin 1978; Adelman 1990). La importancia del crédito estatal, sin embargo, no debe exagerarse. Como es sabido, el dinero barato estaba lejos de constituir el elemento distintivo que explica el éxito del agro pampeano; por otra parte, las condiciones crediticias ofrecidas por la banca pública no eran sustancialmente distintas a las de las casas privadas - aun cuando contribuyeron a fijar los parámetros de la política de préstamos de estas casas. De hecho, la evidencia disponible sugiere que los empresarios rurales recurrieron repetidamente a los servicios de la banca privada para darle mayor amplitud al giro de sus negocios (Hora 2002). Por otra parte, desde muy temprano el crédito 
ofrecido por las instituciones públicas no estuvo orientado exclusivamente a atender los requerimientos de este grupo social (Sabato 1989).

En síntesis, a la luz de esta breve exploración de las características de los mercados de tierra, capital y trabajo en el período de apogeo de la economía de exportación, se observa que la posición de los actores que constituían el núcleo de la elite económica no enfrentaba amenazas ni suscitaba conflictos. El éxito del capitalismo agrario hizo posible una notable distribución de riqueza (de la que dan testimonio, por ejemplo, los elevados niveles salariales y las remesas de los inmigrantes a sus países de origen), y contribuyó a forjar amplios acuerdos sociales, en su mayoría implícitos, que aseguraron que su reproducción preservase el lugar central de la elite rural en la distribución de la riqueza. Por otra parte, y a diferencia de lo que sucedía en otros sectores de la economía (como el industrial, mucho más dependiente de protección arancelaria [Hora 2009b]), el sector agrario pampeano en su etapa de apogeo no solicitaba el apoyo del Estado más que sus funciones básicas de garante del orden público y de instancia superior de sanción de los contratos. Y, en este período, el Estado logró progresos considerables en estas funciones, vía la profesionalización de sus agentes y también gracias a los apoyos que recabó entre empresarios menos poderosos también comprometidos con las líneas maestras del patrón de desarrollo exportador.

Una de las consecuencias de este cuadro fue la creciente indiferencia de la elite propietaria frente al problema del control del Estado. El amplio consenso en torno al patrón de desarrollo, sumado a la percepción de que no enfrentaban amenazas a su supremacía, hizo que las preferencias partidarias de los grandes propietarios estuviesen muy influenciadas por factores específicamente políticos, casi siempre carentes de incidencia sobre sus intereses materiales. A ello también contribuyó que el Estado argentino de esas décadas alcanzó un grado de desarrollo institucional (e imparcialidad) que, vista a la luz de su trayectoria previa y posterior, resulta considerable. Figuras cercanas a la elite dirigente podían usufructuar algunos beneficios gracias a su intimidad con los círculos de poder. Pero lo relevante es que quienes se hallaban en la vereda de enfrente podían confiar en que las estructuras del Estado (justicia, fiscalidad, incluso administración local) eran lo suficientemente impersonales como para que sus intereses no fueran afectados de manera decisiva. Ello explica por qué muchos integrantes de la elite económica se dieron el lujo de mostrarse críticos del orden oligárquico. Es el caso de los grandes terratenientes nucleados en la Liga Agraria, que una y otra vez denunciaron el origen advenedizo y corrupto de la dirigencia política, e incluso se movilizaron para combatirla en los comicios, sin que su actitud hostil hacia el orden establecido pusiese en riesgo su patrimonio o su posición. Y también el de Leonardo Pereyra, uno de los mayores terratenientes del país, que incluso prestó su apoyo a las revoluciones radicales de 1890 y 1893, dirigidas a derrocar al gobierno. Sin embargo, este comportamiento no tuvo ningún impacto negativo sobre esta gran fortuna rural, y cuando Pereyra falleció en 1899 era tenido como el hombre más rico del país (Hora 2009a).

\section{Conclusiones}

Este trabajo ha sugerido que los principales determinantes del proceso de emergencia y transformación de la elite económica argentina del largo siglo XIX se captan mejor en un análisis macro, atento al contexto más amplio, especialmente económico, que fijó los grandes parámetros en los que se desenvolvió la acción de estos actores. El estudio de casos individuales o de redes de relaciones puede aportar precisiones y agregar singularidades a este cuadro. Pero el análisis de la gravitación y las características de la elite económica debe 
trascender los casos singulares para atender a las grandes lógicas sociales que definieron el perfil y el peso específico de este grupo. Esta decisión metodológica se justifica por cuanto el ascenso de este grupo no debió enfrentar la oposición de otros sectores de las clases propietarias ni mayores resistencias entre las clases subalternas, ni fue moldeado por un Estado dotado de amplias capacidades de ingeniería social. Esta elite propietaria nació y creció en gran medida como un producto del crecimiento exportador en un área periférica, abundante en recursos naturales pero pobre en historia, demografía e instituciones. Como en pocos lugares de América, esta ecuación moldeó la fisonomía de la elite económica argentina.

De todos modos, conviene prestar atención al timing del proceso de emergencia y las transformaciones experimentadas por la clase propietaria, ya que los rasgos de este grupo cambiaron con el tiempo. Durante el medio siglo posterior a la independencia, el escenario de inestabilidad institucional propio de ese período le dio un perfil más urbano y diversificado a sus emprendimientos. En esa etapa, también, la formación de una cultura política republicana y la movilización popular acotaron el margen de acción de los hombres de fortuna. Con todo, la gran empresa rural ganó terreno, toda vez que se expandió sobre una frontera abierta, y sin mayores conflictos con las clases subalternas rurales.

En la segunda mitad del siglo cobró forma un Estado más poderoso, cuyo personal e iniciativas reflejaban mejor la diversidad regional del país, y en ocasiones despertaron inquietud entre la elite rural. De todos modos, este Estado colocó a la expansión de la economía de exportación entre sus principales prioridades. Ayudado por un contexto internacional muy favorable a los países exportadores de bienes de clima templado, en esas décadas terminó de conformarse una economía capitalista más compleja y dinámica, que impulsó a los actores más prominentes de la elite económica nacional a acentuar su especialización productiva. La formación de grandes empresas de capital extranjero que modernizaron el sector bancario, el sistema de transporte y la comercialización y exportación de productos primarios tuvo consecuencias similares, por cuanto también moldeó los parámetros que definieron a la elite económica antes que nada como una elite agraria, a la vez productora y rentista. En este contexto, el dinamismo exportador sentó las bases de la amplia coalición que, más allá de las disputas por el poder que dividían a la elite dirigente, contribuyó de manera decisiva a asegurar la estabilidad política de la argentina oligárquica, y a asegurarles a los grandes terratenientes la parte del león en los beneficios de ese modelo de crecimiento.

Roy Hora (rhora@unq.edu.ar) é Doutor em História pela Universidade de Oxford (Reino Unido), professor do Departamento de Ciencias Sociales da Universidad Nacional de Quilmes e pesquisador do CONICET.

\section{Referencias}

Adelman, J. 1989. Una cosecha esquiva: los socialistas y el campo antes de la Primera Guerra Mundial. Anuario del Instituto de Estudios Histórico-Sociales, 4, 293-333.

. 1999. Republic of Capital. Buenos Aires and the Legal Transformation of the Atlantic World. Stanford: Stanford University Press.

1990. Agricultural credit in the Province of Buenos Aires, Argentina, 1890-1914. Journal of Latin American Studies, 22(1-2), pp. 69-87.

Amaral, S. 1998. The Rise of Capitalism on the Pampas. The Estancias of Buenos Aires, 1785-1870. Cambridge, UK: Cambridge University Press.

Avellaneda, N. 1865. Estudios sobre las leyes de tierras públicas. Buenos Aires: Imprenta del Siglo.

Bauer, A. 1995. Landlord and Campesino in the Chilean Road to Democracy. In E. Huber; F. Safford, eds. Agrarian Structure and Political Power. Londres/Pittsburgh: University of Pittsburgh Press.

Brown, J. 1979. A Socioeconomic History of Argentina, 1776-1860. Cambridge, UK: Cambridge University Press.

Bulmer-Thomas, V. 1994. The Economic History of Latin America since Independence. Cambridge, UK: Cambridge University Press. 
Cárcano, M.A. 1917. Evolución histórica del régimen de la tierra pública, 1810-1916. Buenos Aires: Librería Mendesky. Cortés Conde, R. 1979. El progreso argentino, 1880-1914. Buenos Aires: Sudamericana.

Ferrer, A. 1963. La economía argentina. Las etapas de su desarrollo y problemas actuales. Buenos Aires: Fondo de Cultura Económica.

Gaignard, R. 1989. La Pampa Argentina. Ocupación - Poblamiento - Explotación. De la Conquista a la Crisis Mundial (1550-1930). Buenos Aires: Solar.

Gallo, E. 1983. La pampa gringa. La colonización agrícola en Santa Fe, 1870-1895. Buenos Aires: Sudamericana.

Garavaglia, J.C. 1999. Patrones de inversión y `elite económica dominante’: los empresarios rurales en la pampa bonaerense a mediados del siglo XIX. In J. Gelman; J.C. Garavaglia; B. Zeberio, eds. Expansión capitalista y transformaciones regionales. Relaciones sociales y empresas agrarias en la Argentina del siglo XIX. Buenos Aires: Tandil/La Colmena.

Gelman, J.; Santilli, D. 2006. De Rivadavia a Rosas. Desigualdad y crecimiento económico. Tomo III. O. Barsky, ed. Historia del Capitalismo Agrario Pampeano. Buenos Aires: Universidad de Belgrano/Siglo XXI Editores.

Gelman, J.; Schroeder, M.I. 2002. Juan Manuel de Rosas contra los estancieros: Los embargos a los `unitarios’ de la campaña de Buenos Aires. Hispanic American Historical Review, 83(3), pp. 487-520.

Giberti, H. 1954. Historia económica de la ganadería argentina. Buenos Aires: Solar/Hachette.

Girbal de Blacha, N. 1980. Los centros agrícolas en la provincia de Buenos Aires. Buenos Aires: FECYC.

Halperin Donghi, T. 1963. La expansión ganadera en la campaña de Buenos Aires, 1810-1850. Desarrollo Económico, 3, pp. $57-110$. 1972. Revolución y guerra. Formación de una elite dirigente en la Argentina criolla. Buenos Aires: Siglo XXI.

1995. The Buenos Aires Landed Class and the Shape of Argentine Politics, 1820-1930. In E. Huber; F. Safford, eds. Agrarian Structure and Political Power. London/Pittsburgh: University of Pittsburgh Press. 2005. Guerra y finanzas en los orígenes del estado argentino: 1791-1850. Buenos Aires: Prometeo Libros

Hanson, S. 1938. Argentine Meat and the British market. Chapters in the History of the Argentine Meat Industry. Stanford/London: Stanford University Press.

Holloway, T. 1980. Immigrants on the Land. Coffee and Society in Sao Paulo, 1886-1934. Chapel Hill, NC: University of North Carolina Press.

Hora, R. 2001. The Landowners of the Argentine Pampas. A Social and Political History, 1860-1945. Oxford: Oxford University Press.

. 2002. Landowning Bourgeoisie or Business Bourgeoisie? On the peculiarities of the Argentine economic elite, 1880-1945. Journal of Latin American Studies, 34(3), pp. 587-623.

. 2005a. Patrones de inversión y negocios en Buenos Aires en la primera mitad del siglo XIX: el ejemplo de Tomás Manuel de Anchorena. Història Econômica \& Història de Empresas, 8(1), pp. 41-82.

. 2005b. Del comercio a la tierra y más allá: los negocios de Juan José y Nicolás de Anchorena (1810-1856). Desarrollo Económico, 44(176), pp. 567-600.

. 2006. El perfil económico de la elite de Buenos Aires en las décadas centrales del siglo XIX. Revista de Historia Económica, 24(2), pp. 297-332.

.2009a. Los Estancieros contra el Estado. La Liga Agraria y la formación del ruralismo político en la Argentina moderna. Buenos Aires: Siglo XXI Editores.

. 2009b. La política económica del proteccionismo en la Argentina, 1870-1914. Investigaciones y Ensayos, 58, pp. 237-283.

.2010. Historia económica de la Argentina en el siglo XIX. Colección Biblioteca Básica de Historia. Buenos Aires: Siglo XXI Editores.

2012a. Los Anchorena: patrones de inversión, fortuna y negocios (1760-1950). América Latina en la Historia Económica, 37, pp. 39-66.

2012b. Great Wealth in Argentina, 1780s-1940s. In 54 Congreso Internacional de Americanistas. Viena.

Jessop, B. 1990. State Theory: Putting the capitalist state in its place. University Park: Penn State Press.

Justo, J.B. 1901. El Programa Socialista del Campo. Buenos Aires: Cooperativa Tipográfica.

Knight, A. 1986. The Mexican Revolution. V. 1. Cambridge, UK: Cambridge University Press.

Laclau, E. 1969. Modos de producción, sistemas económicos y población excedente. Aproximación histórica a los casos argentino y chileno. Revista Latinoamericana de Sociología, 5(2), pp. 276-315.

Lewis, C. 1983. British Railways in Argentina, 1857-1914. A Case Study of Foreign Investment. London: Atholone Press.

Llach, L. 2007. The Wealth of the Provinces: The Rise and Fall of the Interior in the Political Economy of Argentina, 1880-1910. Cambridge, MA. Tesis (Doctorado em Historia). Universidad de Harvard.

Losada, L. 2008. La alta sociedad en la Buenos Aires de la Belle Époque. Sociabilidades, estilos de vida e identidades. Buenos Aires: Siglo XXI Iberoamericana.

Mayo, C .1995a. Landed but not Powerful: The Colonial Estancieros of Buenos Aires (1750-1810). Hispanic American Historical Review, 71(4), pp. 762-779.

.1995b. Estancia y sociedad en la Pampa, 1740-1820. Buenos Aires: Biblos.

Marichal, C. 1995. Modelos y sistemas bancarios en América Latina en el siglo XIX (1850-1880). In P. Tedde; C. Marichal, eds. La formación de los bancos centrales en España y América Latina (siglos XIX y XX). V. I. Madrid: Banco de España. . 1998. La gran burguesía comercial y financiera de Buenos Aires, 1860-1914: anatomía de cinco grupos. In XVI Jornadas de Historia Económica. Quilmes. 
Myers, J. 1995. Orden y virtud. El discurso republicano en el régimen rosista. Bernal: Universidad Nacional de Quilmes. Míguez, E. 1986. La expansión agraria de la pampa húmeda (1850-1914). Tendencias recientes de sus análisis históricos. Anuario IEHS, 1, pp. 89-119.

.2006. ¿Veinte años no es nada? Balance y perspectivas de la producción reciente sobre la gran expansión agraria. In J. Gelman, ed. La historia económica argentina en la encrucijada. Balances y perspectivas. Buenos Aires: Prometeo. 2008. Historia económica de la Argentina. De la conquista hasta la crisis de 1930. Buenos Aires: Sudamericana.

Oddone, J. 1956 [1928]. La burguesía terrateniente argentina. Buenos Aires: Líbera.

Peña, M. 1974. Industria, burguesía industrial y liberación nacional. Buenos Aires: Fichas.

Regalsky, A. 1995. La evolución de la banca privada nacional en Argentina (1880-1914). Una introducción a su estudio. In P. Tedde; C. Marichal, eds. La formación de los bancos centrales en España y América Latina (siglos XIX y XX). V. I. Madrid: Banco de España.

Reguera, A.; Zeberio, O. 2006. Volver a mirar. Gran propiedad y pequeñas explotación en la discusión historiográfica argentina de los últimos veinte años. In: J. Gelman, ed. La historia económica argentina en la encrucijada. Balances y perspectivas Buenos Aires: Prometeo.

Sabato, H. 1989. Capitalismo y ganadería en Buenos Aires. La fiebre del lanar, 1840-1890. Buenos Aries: Sudamericana. . 1998. La política en las calles. Entre el voto y la movilización ciudadana, Buenos Aires, 1862-1880. Buenos Aires: Sudamericana. 2012. Historia de la Argentina, 1852-1890. Buenos Aires: Siglo XXI.

Sábato, J. 1991. La clase dominante en la Argentina moderna. Formación y características. Buenos Aires: GEL.

Salvatore, R. 2003. Wandering Paysanos: State Order and Subaltern Experience in Buenos Aires during the Rosas Era (1820-1860). Durham: Duke University Press.

Schvarzer, J. 1991. Empresarios del pasado. La Unión Industrial Argentina. Buenos Aires: GEL.

Scobie, J. 1964. Revolution on the pampas. A Social History of Argentine Wheat, 1860-1910. Texas: Texas University Press. Smith, P. 1969. Politics and Beef in Argentina. Patterns of Conflict and Change. New York: Columbia University Press.

Solberg, C. 1971. Rural Unrest and Agrarian Policy in Argentina, 1912-1930. Journal of Inter-American Studies and World Affairs, 13(1), pp. 18-52.

Topik, S. 1987. The Political Economy of the Brazilian State, 1889-1930. Austin: Texas University Press. Toulchin, J. 1978. El crédito agrario en la Argentina, 1910-1926. Desarrollo Económico, 18(71), pp. 381-408.

\section{ABSTRACT}

This article analyses the 1810-1914 Argentine economic elite's most salient features. The most important interpretations on the history and characteristics of this group are discussed, drawing attention to the major strenghts and limitations of different theoretical and empirical schools of analysis. Even though this article focuses on the economic elite, it also pays some attention to the state and the economic environment in which wealthy capitalists were forced to act. It suggests that state and market need to be taken into account in order to understand the basic characteristics of this group. This paper suggests that the analysis of the economic elite has paid too much attention to the realm of politics, and that economic structures need to be given more analytical weight. Rather than new information or data, this paper offers a discussion of current and past literature.

KEYWORDS: economic elite; Argentina; nineteenth century; historiography; rural economy. 